\title{
Electrochemical cell design and impedance spectroscopy of cement hydration
}

\author{
Aldo F. Sosa Gallardo ${ }^{1}$ and John L. Provis ${ }^{1, *}$ (1) \\ ${ }^{1}$ Department of Materials Science and Engineering, The University of Sheffield, Sir Robert Hadfield Building, Mappin St, \\ Sheffield S1 3JD, UK
}

Received: 20 August 2020

Accepted: 25 September 2020

Published online:

12 October 2020

(C) The Author(s) 2020

\begin{abstract}
Understanding the complexity of the chemical and microstructural evolution of cement during hydration remains a controversial subject, and although numerous techniques have been used to assess this process, further insight is still needed. Alternating current impedance spectroscopy has been demonstrated to be a sensitive and powerful technique for cement characterisation in both fresh and hardened states; however, it has also shown certain experimental limitations (e.g. data interpretation, electrode, and parasitic effects) that prevent its wider acceptance. This study assesses electrochemical cell design and the impedance response during cement hydration. The results show that a significant decrease in the parasitic effects at high frequencies (caused mainly by leads and electrode effects) can be achieved through an optimal cell design and impedance measurements correction, enabling correlation of impedance measurements to particular aspects of the cement hydration process. However, due the limited solid phase microstructural development and the high conductivity of cement paste at low degrees of hydration, the parasitic effects could not be fully eliminated for fresh or early-age cement pastes.
\end{abstract}

\section{Introduction}

Portland cement is one of the most-used materials in the world ( $>4$ Gt p.a.), but hardens and gains strength via what is arguably one of the most chemically complex non-biological reaction processes that is studied by scientists and engineers. Therefore, there are still important aspects that are not fully understood about this material. Cement hydration is critically important, since it determines the final microstructure, physical, and mechanical properties of the hydrated cement paste.

The hydration process consists of a series of simultaneous and sequential chemical reactions, involving dissolution of multi-mineral clinkers and ancillary sulphate phases, water consumption, hydrate product formation, heat release, and the

Handling Editor: M. Grant Norton.

Address correspondence to E-mail: j.provis@sheffield.ac.uk 
development of a solid microstructure containing a high ionic-strength pore solution [1-4]. The full understanding of cement hydration is of great importance to enhance its early and final properties and to achieve better performance (technical and environmental) in its applications.

Many different techniques, tools, and interpretation methods have been used to assess cement hydration. One of these techniques is alternating current impedance spectroscopy (ACIS). Although ACIS has been demonstrated to be an effective and powerful technique and used in many studies in the cement research field due to the possibility to obtain electrical, chemical, and microstructural information for different materials, it is not yet fully accepted in practice due to its limitations (e.g. electrode effects, parasitic effects at high frequencies, instrument drawbacks, and data interpretation) [5-10].

ACIS measures the electrical response of a system (electrolyte-electrode) as a function of frequency by applying a sinusoidal voltage perturbation and is commonly studied as a function of time and/or temperature. Because cement can be considered as a circuit (electrochemical system) with a complex behaviour made up of electrical components (e.g. resistive and capacitive behaviour), cement hydration is able to be assessed by this technique. ACIS measurements are often analysed as complex impedance spectra (conventionally represented as $Z^{*}=Z^{\prime}-j Z^{\prime \prime}$, where $Z^{\prime}$ is the real part, $j=\sqrt{ }-1$, and $-Z^{\prime \prime}$ is the imaginary part). The measurements obtained are divided into the high-frequency region (i.e. material bulk response), the low-frequency region (i.e. material-electrode response), and the intercept point between the high-low-frequency response (i.e. material resistivity) [11-13].

ACIS is a highly sensitive technique and its measurements can be affected by parasitic effects (e.g. inductance and capacitance) which could arise from the system under analysis, the cell design, the experimental procedure and/or from the leads configuration and to obtain accurate and reliable data which are often overlooked leading to data misinterpretation. So, ACIS experimentation for in situ analysis of cements requires significant care in experimentation. For example, a small cable in combination with a low-impedance cell will exhibit stray inductance, which will increasingly oppose the current flow as the frequency increases [9, 14, 15]. In addition, effects such as magnetic coupling,

produced by the current flowing in leads, can produce a perturbation (false inductance) in the impedance measurements $[5,10,16,17]$.

To enable more accurate assessment of the hydration of cement by ACIS, the aim of this paper is to investigate and evaluate the parameters that could produce parasitic effects in the ACIS measurements, and to provide guidance for appropriate experimental protocols. Understanding these parameters and their influence on the ACIS measurements is crucial in obtaining reliable data and thus correct data interpretation.

\section{Materials and methods}

\section{Sample preparation}

Samples were prepared at room temperature $(20 \pm$ $3{ }^{\circ} \mathrm{C}$ and $50 \pm 15 \%$ relative humidity) by mixing water with white Portland cement (wPc; Lafarge Blue Circle Snowcrete) classified as CEM I 52.5R under BS EN 197-1, at a water to cement ratio (w/c) of 0.45 . The chemical composition and physical properties of the wPc are given in Table 1.

Each $300 \mathrm{~g}$ sample was hand-mixed by combining the components for $3 \mathrm{~min}$ to form a homogeneous paste, and then transferred into a custom-designed cell as described below for ACIS measurements. Prior to the start of the analysis, all samples were vibrated for 2 min to reduce entrapment of air bubbles.

Table 1 Chemical composition of $\mathrm{wPc}$ as determined by X-ray fluorescence analysis and median particle size $d_{50}$ as determined by laser granulometry

\begin{tabular}{lc}
\hline Compound (wt.\%) & wPc \\
\hline $\mathrm{SiO}_{2}$ & 23.7 \\
$\mathrm{Al}_{2} \mathrm{O}_{3}$ & 3.9 \\
$\mathrm{CaO}$ & 66.5 \\
$\mathrm{Fe}_{2} \mathrm{O}_{3}$ & 0.2 \\
$\mathrm{MgO}$ & 0.9 \\
$\mathrm{Na}_{2} \mathrm{O}$ & 0.23 \\
$\mathrm{~K}_{2} \mathrm{O}$ & 0.5 \\
$\mathrm{SO}_{3}$ & 2.6 \\
$\mathrm{TiO}_{2}$ & - \\
$\mathrm{Others}$ & 1.0 \\
${ }^{*} \mathrm{LOI}$ & 1.2 \\
$\mathrm{~d}_{50}(\mu \mathrm{m})$ & 11.0 \\
${ }^{*} \mathrm{LOI}:$ Loss & on ignition at \\
$950{ }^{\circ} \mathrm{C}$ &
\end{tabular}




\section{Instrumental analysis}

The samples were subjected to ACIS measurements using an impedance analyser with a single channel (Metrohm AutoLab, PGSTAT204) [18] connected to a custom two-electrode cell design (Fig. 1). The initial custom cell was designed using a cylindrical polypropylene container $(\phi 6 \times 11.2 \mathrm{~cm})$ and two threaded stainless-steel electrodes $(\phi 0.5 \times 8 \mathrm{~cm})$. The design of the initial cell was based on the characteristics of its constituents, simplicity of the design, low cost of the materials, its performance, reproducibility, and convenience for laboratory experimentation (Table 2). To avoid sample leakage, the electrodes were inserted in the bottom face of the container and attached with a hard-plastic adhesive.

ACIS measurements (50 data points per cycle) were collected at room temperature over a frequency range of $100 \mathrm{~Hz}$ to $1 \mathrm{MHz}$, an applied perturbation amplitude of $10 \mathrm{mV}$, and a current range up to $1 \mathrm{~mA}$. The frequency range $1 \mathrm{MHz}-100 \mathrm{~Hz}$ was found to be representative of the most important behaviour in this analysis (i.e. cement bulk response, cementelectrode response). Measurements were conducted in triplicate. Data were obtained every 5 min during the first $24 \mathrm{~h}$ after mixing. The measurements were consistent to within $8 \%$ at $5 \mathrm{~min}, 3 \%$ at $24 \mathrm{~h}$, and the timing of the main features observed was repeatable to within $\pm 5 \mathrm{~min}$. The data obtained from this technique are conveniently represented as a Nyquist plot, where the imaginary component is conventionally plotted as $-Z^{\prime \prime}$ and the real component is $Z^{\prime}$ of the complex impedance formalism, $Z^{*}$.

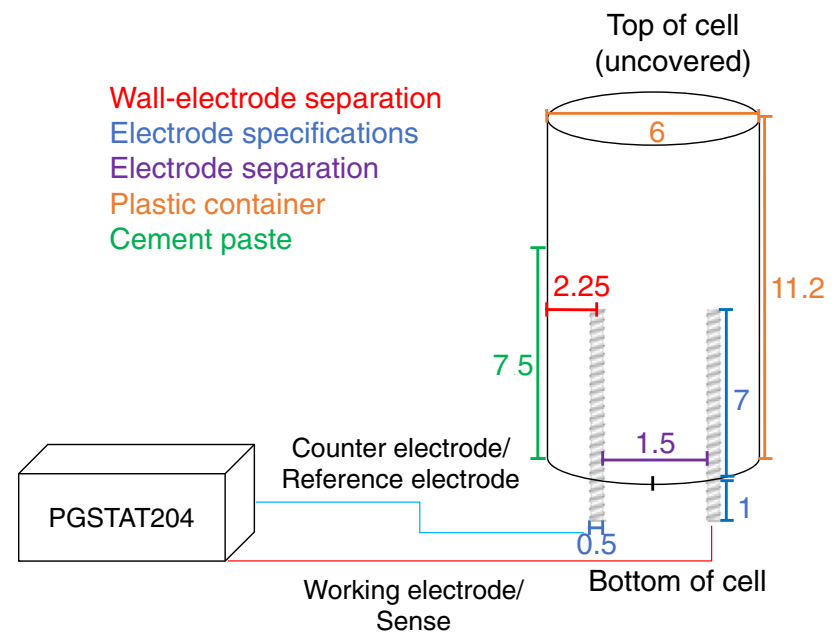

Figure 1 ACIS initial cell design diagram (scale in $\mathrm{cm}$ ).

\section{Experimental methodology}

To assess the hydration process of cement by ACIS, the experimentation was divided into two stages.

The first stage objective is, by evaluating different cell designs (changing one parameter at a time), to select a custom cell design and procedure which could be capable of providing reliable impedance measurements with the minimum noise and external interference (parasitic effects), for wPc at early hydration periods.

To achieve this, the initial cell set-up (Table 3) involved the selection of an electrode attachment method capable of maintaining the electrodes at a fixed position in the container, avoiding sample leakage and unwanted contributions to the ACIS measurements.

To verify linearity of the ACIS response, and the sensitivity of the cement system at early ages, evaluation of the amplitude of perturbation was carried out, followed by an analysis of the leads (identified as the main source of parasitic effects). Finally, the sample/cell geometry was evaluated.

After selecting the initial cell set-up parameters, the second segment (Table 4), electrode effects, was focused on comparing the impedance response of wPc to different electrode specifications such as the surface area, material, and electrode position.

After evaluation of the first stage, the second experimental stage was carried out by the custom cell calibration and the ACIS measurements correction procedure. The calibration was determined by measuring the impedance response of the cell in a short circuit arrangement (without sample) before the samples were tested, to enable minimisation of the parasitic effects associated with the cell components and leads. The measurement correction was made at each frequency, considering the ACIS response of the cement sample and the parasitic effects as additional quantities in the final ACIS measurements [19-21]. The selection of the final cell design was carried out through optimising the cell components according to their capacity to minimise parasitic effects in the impedance measurements.

\section{Results and discussion}

In previous investigations, the hydration of white Portland cement (wPc) was studied by ACIS during the first $72 \mathrm{~h}$ after mixing [22]. The impedance 
Table 2 Basis of the initial cell design [1-9]

\begin{tabular}{ll}
\hline Two-electrode set-up & $\begin{array}{l}\text { Commonly used to measure the potential and bulk resistance across the sample } \\
\text { Allows the assessment of electrochemical impedance measurements at high frequency ( }>100 \mathrm{kHz})\end{array}$ \\
Allow measuring the bulk properties of the sample & Allow using a small perturbation amplitude without affecting the measurement \\
Polypropylene container & Inexpensive \\
Inert to the majority of chemical reactions & Suitable for alkaline solutions \\
& More volume per unit wall area (cylindrical geometry) \\
Electrode properties & Stainless steel has suitable corrosion resistance properties in high alkaline solutions \\
Material & High active surface area \\
Geometry and dimensions & Allow more current density at the surface \\
Potential and current distribution is uniform & Electric field across the sample is uniform \\
Increase measurement sensitivity
\end{tabular}

Table 3 Initial cell design and experimental specifications (baseline setting)

\begin{tabular}{|c|c|}
\hline Parameter & Specifications \\
\hline Electrode attachment & Method: hard-plastic adhesive and SS nuts \\
\hline System linearity & Amplitude $(\mathrm{mV}): 1$ and $\mathbf{1 0}$ \\
\hline Leads effects & $\begin{array}{l}\text { Height in relation to the ground }(\mathbf{1 0} \mathrm{cm}) \text {, twisted leads, position: vertical and horizontal (Fig. 8) } \\
\text { Length }(\mathrm{cm}): \mathbf{1 5 0}, 200 \text {, and } 250\end{array}$ \\
\hline
\end{tabular}

Table 4 Electrode effects test specifications (baseline setting)

\begin{tabular}{ll}
\hline Parameter & Specifications \\
\hline Surface area & Diameter $(\mathrm{cm}): \mathbf{1}, \mathbf{0 . 5}$, and 0.3 \\
& Length $(\mathrm{cm}): 1,2,4,6$, and $\mathbf{7}$ \\
& Texture: threaded and flat \\
Material & SS and mild steel \\
Position & Electrode separation $(\mathrm{cm}): \mathbf{1 . 5 , 3}$, and 6 \\
& Electrode position: bottom, top, vertical, and horizontal \\
\hline
\end{tabular}

measurements obtained were affected by parasitic inductance effects at high frequencies (that appear below the $Z^{\prime}$ axis intercept), potentially leading to unreliable data interpretation.

Figure 2 shows the impedance spectra of $\mathrm{wPc}$ during the first $72 \mathrm{~h}$. During all experimentation, it can be noticed that the high-frequency data (below the $Z^{\prime}$ axis, red line) show parasitic inductive effects mainly related to the effects of the leads, and influenced by factors including the high conductivity and low microstructural development of the cement paste, magnetic coupling and electrode effects, cell design, potentiostat response, and working frequency range $[16,20,21]$. With an increase in frequency, the inductance increases, and as a result, the capacitiveresistive arc at high frequencies disappears. This indicates that the information in that frequency range is altered by the inductance effects and cannot be 


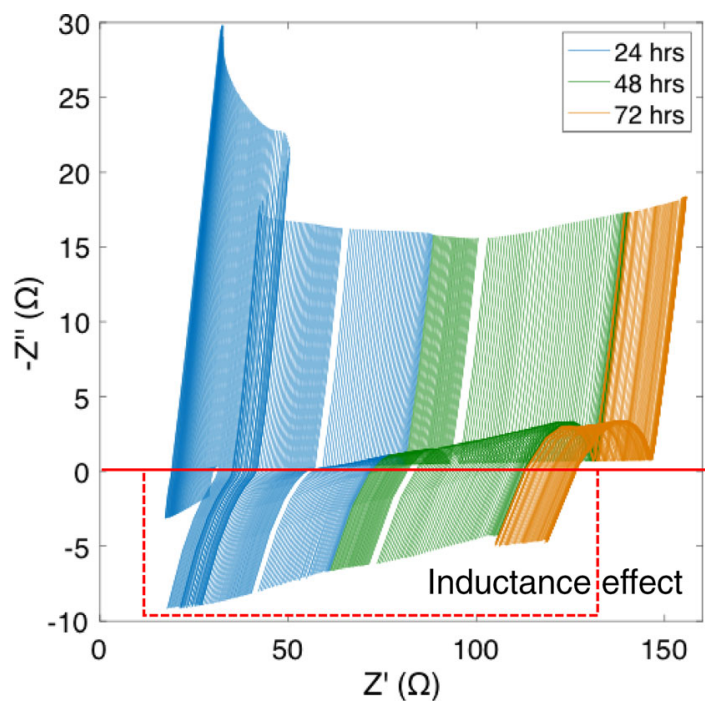

Figure 2 ACIS data during the first $72 \mathrm{~h}$ of wPc hydration. Dashed line indicates the part of the data showing a strong influence of inductance, falling below the Z' axis.

analysed or considered reliable data for characterisation of the cement. Even though the parasitic inductance effects were only visibly affecting the high-frequency data, it was possible that all frequency ranges (high, medium, and low) were affected by the same parasitic effects since they can influence potential-working electrode response and the measured capacitance at different frequencies.

The ACIS measurements obtained were evaluated by examination of Lissajous and resolution plots, and Nyquist plots. The information obtained regarding the cement material response at early age was limited because of the high conductivity of the cement paste produced by the water content, the high ionic strength of the pore solution, the hydration kinetics, and the continuous and open pore structure $[14,23,24]$.

\section{Initial cell set-up}

\section{System linearity}

ACIS relies on the use of an amplitude small enough to obtain a linear response which can be expressed analytically. The linearity of the system is directly related to the amplitude that is applied to the system. To find the optimal amplitude permutation and verify the linear response for cement systems, raw impedance data were used to generate Lissajous and resolution plots. The amplitude must be small enough to minimise perturbation of the material behaviour during cement hydration, but large enough that a high-fidelity signal can be recorded.

The Lissajous plots (e.g. Fig. 4) show the AC potential ( $x$-axis) and the AC current (y-axis). The information obtained allows the verification of the linearity of the ACIS response in which the AC amplitude should be small enough so that the response of the electrochemical cell can be considered to be linear, but large enough to measure the system response [13, 25-27]. The resolution plots (e.g. Fig. 5) show the AC current and the AC potential (y-axis) as a function of time ( $x$-axis). The information obtained allows measurement of the sensitivity of the system and the noise significance in the processed data. Two different amplitude perturbations $(10 \mathrm{mV}$ and $1 \mathrm{mV}$ ) were used to verify the sensitivity and linear response of the experimental procedure for cement systems, in the frequency range $1 \mathrm{MHz}$ to $100 \mathrm{~Hz}$ and at a fixed current of $1 \mathrm{~mA}$.

At an amplitude of $10 \mathrm{mV}$ (Fig. 3), the Lissajous plots show that the linearity of the ACIS response is maintained, with central symmetry of a straight line with respect to the origin of the plots at each frequency. In the same way, the resolution plots (Fig. 4) show a high resolution of both signals at each frequency.

Conversely, at an amplitude of $1 \mathrm{mV}$ (Fig. 5), the Lissajous plots show a strongly nonlinear response, as the central symmetry of the plot is not maintained and the shape is disturbed by noise. Likewise, the resolution plots (Fig. 6) show a high resolution for the

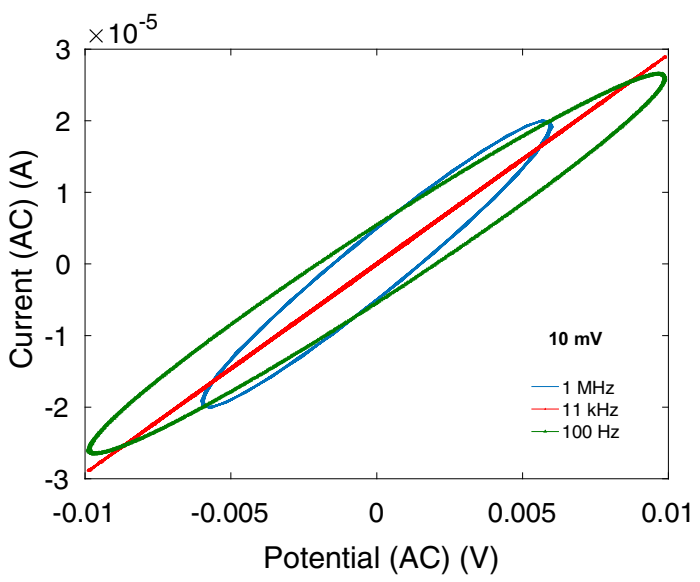

Figure 3 Lissajous plot for wPc paste at 5 min after mixing, amplitude of $10 \mathrm{mV}$. 

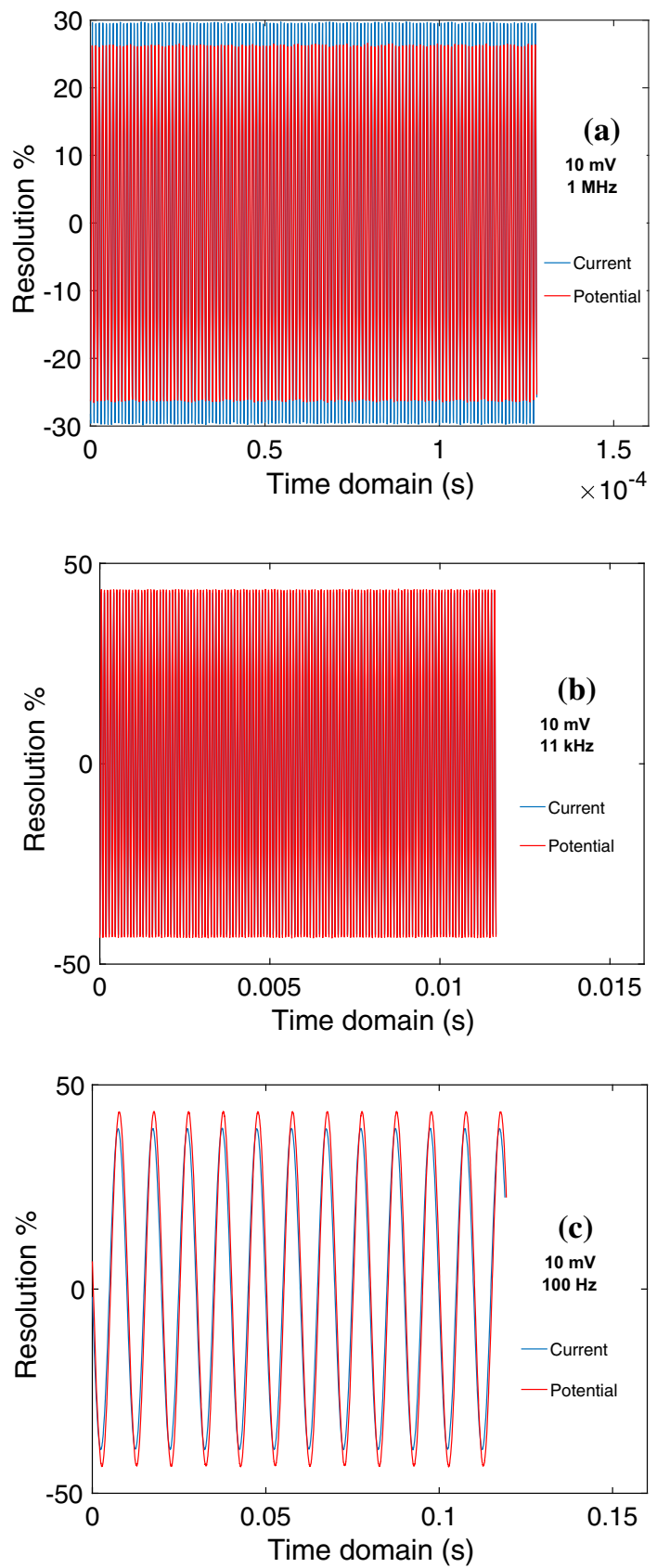

Figure 4 Resolution plots of wPc at 5 min after mixing and using a perturbation amplitude of $10 \mathrm{mV}$ : frequency a $1 \mathrm{MHz}$, b $11 \mathrm{kHz}$, and c $100 \mathrm{~Hz}$.

current signal, but a low resolution for the potential signal.

To avoid nonlinear effects and based on the evaluation between both amplitudes, a linear response and accurate data can be obtained using $10 \mathrm{mV}$ as the preferred amplitude for analysis of cement systems in the apparatus described here. This amplitude is selected due to the reduction of the errors that could

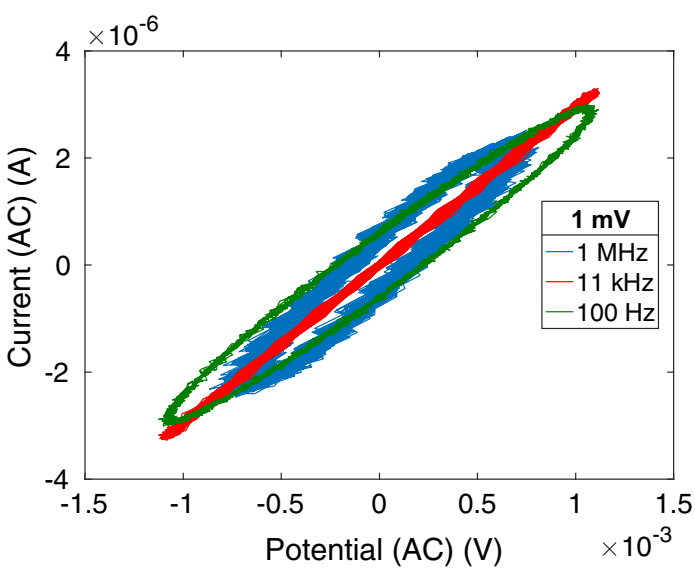

Figure 5 Lissajous plot of wPc paste at 5 min after mixing, amplitude $1 \mathrm{mV}$.

be produced by charge-transfer resistance, noise, and polarisation during the impedance measurements. Smaller amplitudes will degrade and distort the impedance measurements, leading to inaccurate measurements and nonlinear response [28-31].

\section{Electrode attachment}

The electrode-cell attachment was assessed by comparison of the ACIS responses measured during wPc hydration using the SS electrodes attached with SS nuts, and with hard-plastic adhesive. Figure 7 shows the ACIS response of $\mathrm{wPc}$ as a function of the electrode attachment method, at hydration times of $5 \mathrm{~min}$ and $24 \mathrm{~h}$. The electrodes that were attached with hard-plastic adhesive show fewer inductance effects at high frequency (likely to impact the impedance measurements) for both ages.

The electrodes attached with SS nuts show higher inductance effects due to the decrease in resistance as a result of the increase in the number of flux lines and amount of energy stored in the electrodes. Also, the changes in the ACIS values at both ages, as a result of an increase in the electrode surface area and a decrease in the electrode separation at the bottom of the cell produced by the attachment of the SS nuts to the SS electrodes, mean that an uneven current is flowing through the SS electrodes and nuts, which are acting as both working and counter-electrodes (Fig. 1) [32-34].

For the cement at an early stage of hydration, with both attachment methods, it is not possible to identify a high-frequency semicircular arc, as the measured values fall below the $Z^{\prime}$ axis. As mentioned before, 

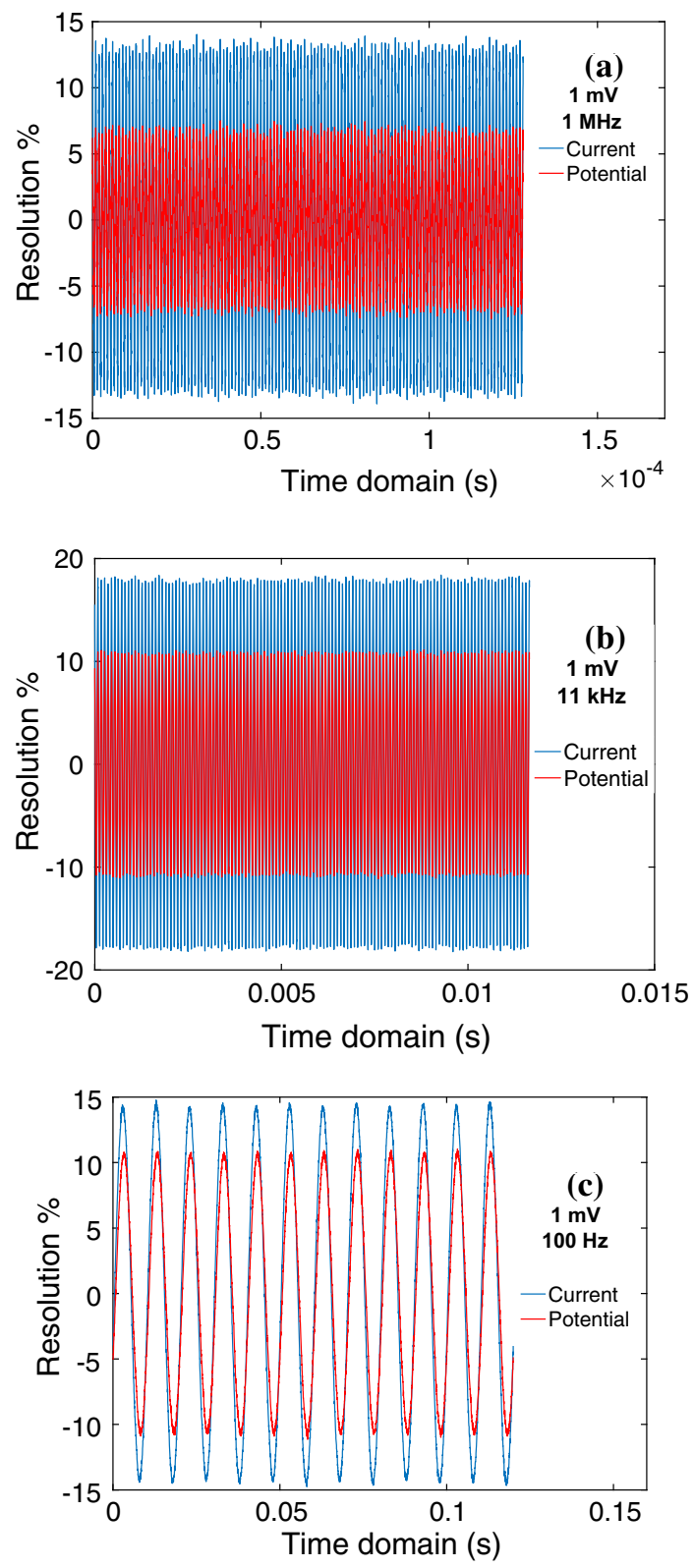

Figure 6 Resolution plots of wPc at 5 min after mixing and using a perturbation amplitude of $1 \mathrm{mV}$ : frequency a $1 \mathrm{MHz}, \mathbf{b} 11 \mathrm{kHz}$, and c $100 \mathrm{~Hz}$.

this is probably due to the high conductivity of the fluid cement paste with a highly connected aqueous phase of relatively high ionic strength, and the parasitic effects of the leads and cell. At longer ages, cement hydration proceeds, inductance decreases, and an increasing tendency in the resistance is observed, progressively yielding a more noticeable high-frequency semicircular arc. This can be attributed to the microstructural development, water consumption, and reduction of the connectivity of the

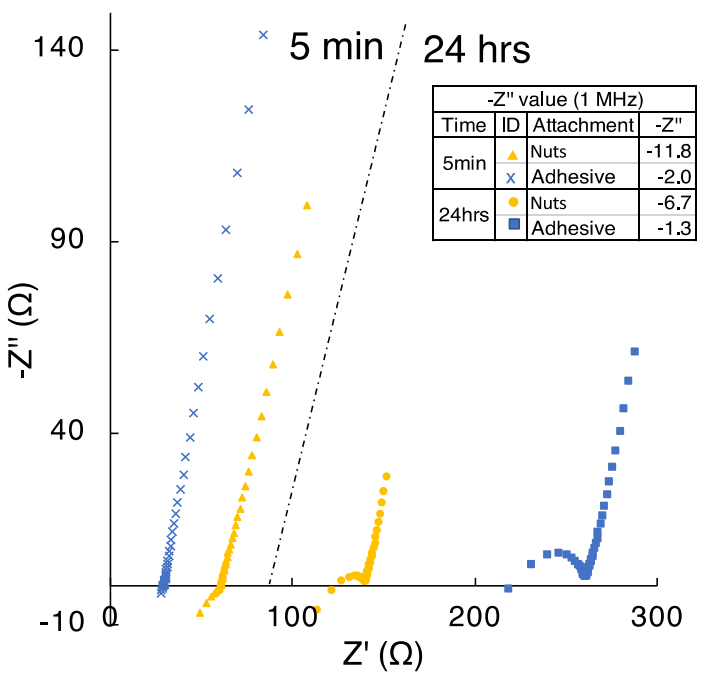

Figure 7 ACIS measurements of wPc at different ages, testing electrode attachment methods as indicated.

pores [14, 16]. These trends are discussed in the "Calibration and measurement corrections" section.

\section{Lead effects}

Parameters related to the leads, such as length and diameter, degree of grounding and shielding, weak end contacts, and positioning, are some of the main sources of noise and error in ACIS measurements. Parasitic perturbations produced due to the leads have been found in both high- and low-impedance cells in the form of stray capacitance or stray inductance, respectively $[35,36]$. These measurement perturbations are difficult to evaluate due to the interconnecting wiring, the external environment, and the parameters previously mentioned. For example, the AC current that passes through the current-transporting leads produces a magnetic field which couples to the leads from which the potential is measured, leading to unwanted AC voltages which could lead to mutual inductance errors in the ACIS measurements. Previous studies have proposed different solutions to minimise these parasitic perturbations [15, 19, 37].

To evaluate the lead effects on ACIS measurements for cement pastes at early age, different lead positions and lengths were analysed using the initial cell design. Figure 8 shows a schematic representation of the parameters evaluated; (a) distance of the leads between the working surface and the electrochemical cell, (b) twisting of leads, (c) alignment of connections 
between the leads and the SS electrodes, and (d) lead length.

Figure $9 a, b$ shows that there is not a significant change in the impedance spectra as a result of changing the distance of the leads between the working surface and the electrochemical cell, or by twisting the leads. These results confirm that these lead arrangements (i.e. conductor, insulation, binder, braid, jacket, and connectors) are suitable for the following experiments.

Similarly, there are no meaningful changes in the ACIS measurements when changing the alignment of the connections between the leads and the SS electrodes (Fig. 9c), since the SS electrode position $(3 \mathrm{~cm}$ separation distance) is restricted and does not allow the leads to separate further from each other. Also, the results are an indication that the impedance measurements are not affected by the magnetic coupling or the pickup effects produced by the low-intensity magnetic field of the leads.

However, it can be observed that an increase in the lead length has a meaningful impact on the ACIS measurements. Figure $9 d$ shows the changes in parasitic effects and $Z^{\prime}$ values as the length of the leads increases. The lead length increase raises the resistance, leading to a negative impact on the measured signal amplitude as a result of the wave deterioration as the leads move away from the energy source. Also, when AC is applied, a phase shift between the applied amplitude and the current can occur $[33,37,38]$. The following experiments were therefore conducted using the standard cables $(150 \mathrm{~cm})$; it was not possible to further reduce the length of the leads due to the limitations of the equipment available.

\section{Electrode effects}

The cement paste parameters measured by ACIS can be divided into two categories: the first set corresponds to the properties and behaviour of the cement itself (e.g. conductivity, kinetics, pore solution), and the second relates to the electrode-cement interaction (e.g. diffusion, adsorption, capacitance, electrical double layer capacitance). ACIS measurements can be affected by the electrode performance which depends on the system under analysis, the electrode specifications (e.g. surface area and material), and the electrode position. A significant change in any of these parameters will have a significant impact on the electrode performance and stability, which may lead to collection of erroneous data or misinterpretation of ACIS measurements [39].

An ideal electrode design should have a surface area which is able to deliver a uniform current density to ensure a uniform potential distribution over the electrodes and the sample [40]. The electrode alignment needs to be symmetrical between the WE and RE not only to avoid uneven current distribution, but also to decrease errors produced by differences in potential distribution. In addition, the study of the electrode material should be performed considering the sample material under investigation, since interactions with the sample can affect the electrode surface (e.g. corrosion and/or passivation layers), leading to an unwanted contribution to the measured impedance, and erroneous data interpretation. Cement paste and its pore solution have a highly alkaline environment ( $\mathrm{pH}$ around 12 to 14) which can in turn influence the passivation properties of the electrode material $[2,4,19,41]$. The electrode material needs to have good electrical properties and performance to obtain good electric field distribution and
Figure 8 Illustration of the lead parameters evaluated. (a) Leads height

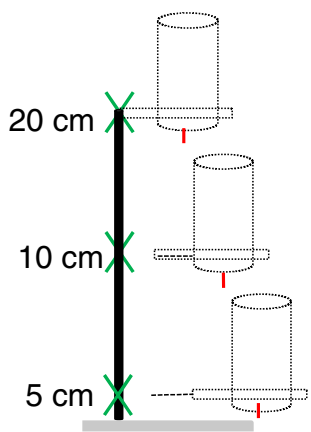

(b) Leads twisting

(c) Alignment

(d) Length
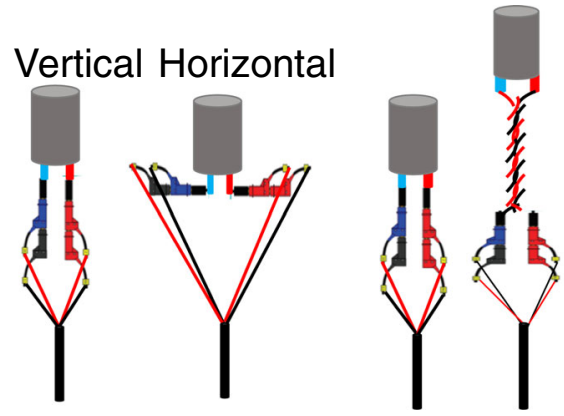
Figure 9 ACIS measurements with different lead parameters: a height above working surface, $\mathbf{b}$ twisting, $\mathbf{c}$ alignment, and $\mathbf{d}$ length.
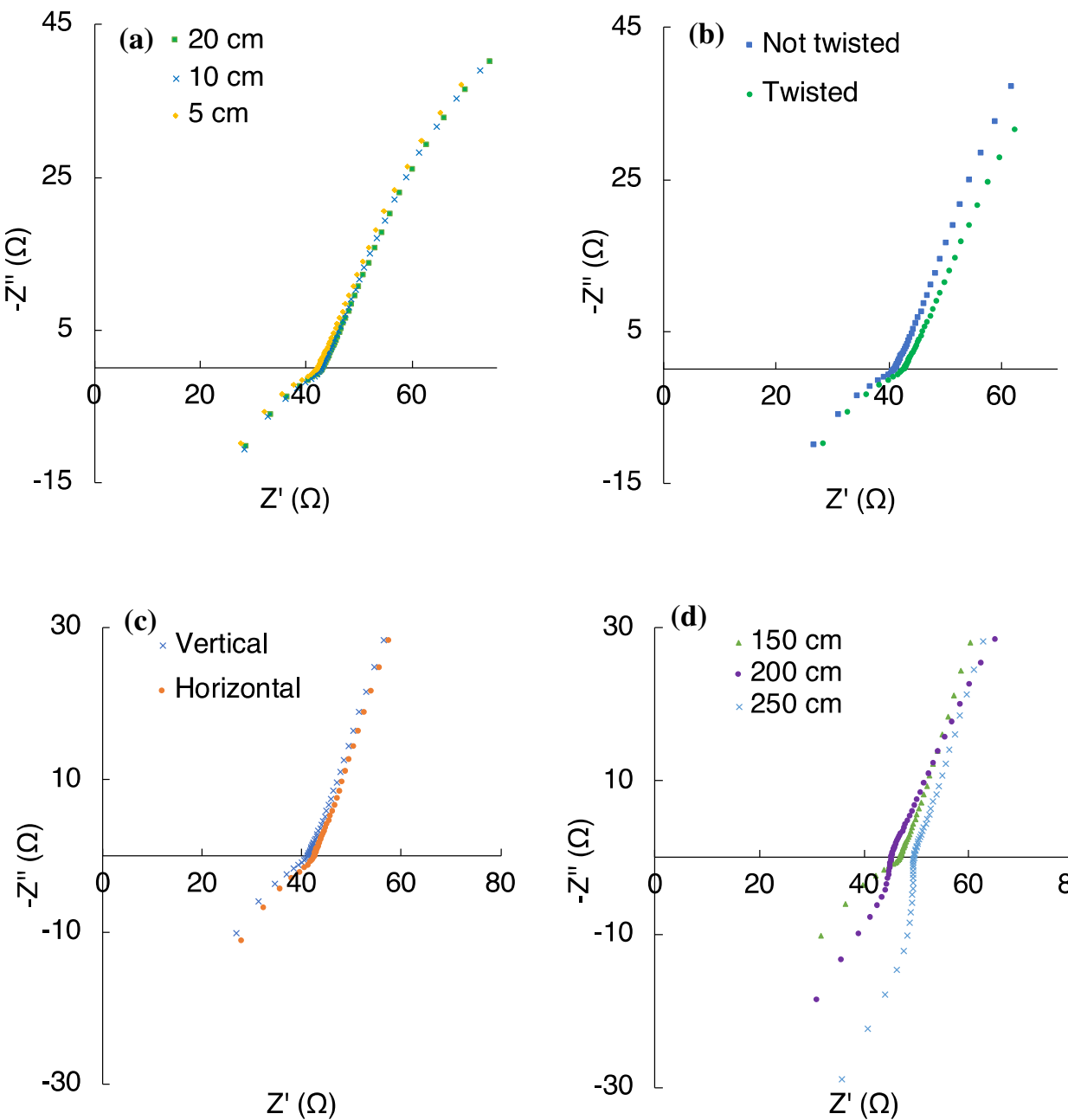

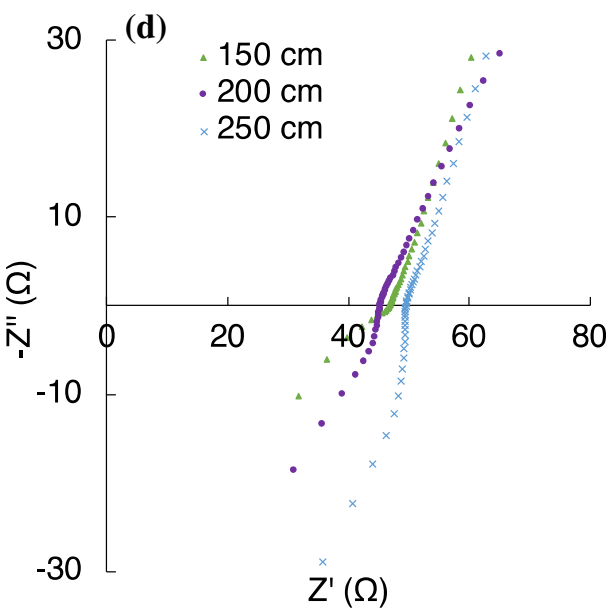

reduce unwanted impedance responses. It is fundamental to understand the electrode effects to obtain a better cell configuration which could yield more, and more reliable, information about the cement system.

This section presents discussion of the influence of the electrode effects on cement ACIS measurements, intending to obtain insight into the relationship between the electrode effects and the ACIS response. To enable comparison of the results obtained using electrodes of differing surface areas, the results were normalised by multiplying the impedance obtained by the electrode surface area under investigation.

\section{Electrode surface area}

Figure 10 shows the electrode surface area effects in the cement ACIS measurements of $\mathrm{wPc}$ pastes. At early age (5 min after mixing the cement pastes), the impedance values are slightly affected by the changes in the electrode surface area when either length
(Fig. 10a) or diameter (Fig. 10b) is varied. As the electrode surface area increases, the parasitic inductance effects are seen at high frequencies, and the values on the $Z^{\prime}$ axis increase, showing a correlation between the electrode surface area and the impedance values. The information at high frequency is obscured due to parasitic inductance effects which arise from the lead effects (as discussed in the preceding section) and the state of the cement paste (low developed microstructure and highly conductive). At longer ages $(24 \mathrm{~h})$, the results show a higher influence of the electrode surface area on the ACIS measurements, following the same tendency as at early ages. The increase in the resistance and the reduction of the inductance effects are produced by the microstructural development of the cement paste. These changes can be observed through the appearance of a high-frequency semicircular arc at longer ages.

It is important to notice that changes in the ACIS measurements produced by changing the electrode 

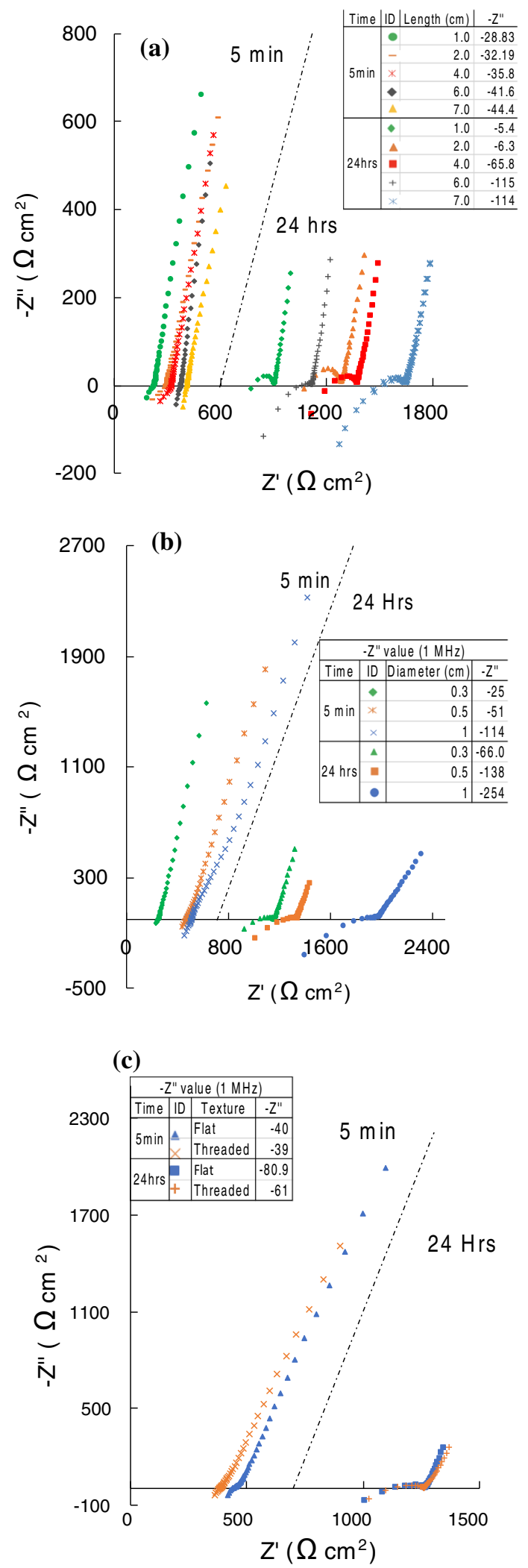

Figure 10 ACIS response of wPc and gPc pastes at $5 \mathrm{~min}$ and $24 \mathrm{~h}$ after mixing, varying electrode parameters as indicated in the legend: a electrode length, $\mathbf{b}$ electrode diameter, and $\mathbf{c}$ texture. texture from threaded to flat (Fig. 10c) are small at early age, and almost null for a more mature cement paste. These changes will not influence the effective surface area drastically (in terms of the distribution of electrical flux lines), but they will have an impact on the contact between the electrodes and the cement paste.

Parameters measured by ACIS such as electrical double layer capacitance (EDLC), electron transfer resistance (ETR), and the uncompensated electrolyte resistance will depend on the ionic concentration and the ion types in the aqueous phase, the temperature, the reaction kinetics, the electrode surface area, and the current distribution [12, 42-45]. As the electrode surface area increases, the electrode-sample reaction kinetics, the parameters previously mentioned, and the current distribution will rise, leading to differences in the ACIS response as observed in the results (Fig. 10). Considering the experimental system as a circuit, as the electrode surface area is changed, the magnetic flux through the circuit, the amplitude, and current dispersion through the cement paste also change, affecting the parasitic effects and the impedance values.

Figure 11 shows the short circuit cell ACIS measurements obtained from two different SS electrode diameters. ACIS measurements show $-Z^{\prime \prime}$ negative values in which inductance effects $\left(-Z^{\prime \prime}\right)$ and the resistance values ( $Z^{\prime}$ axis), produced by the leads, the cell, and the frequency dependence of both parasitic components, are observed [10, 20, 21]. The reason for a lower impedance value is explained by Eq. 1 (based on the comparison between both diameters).

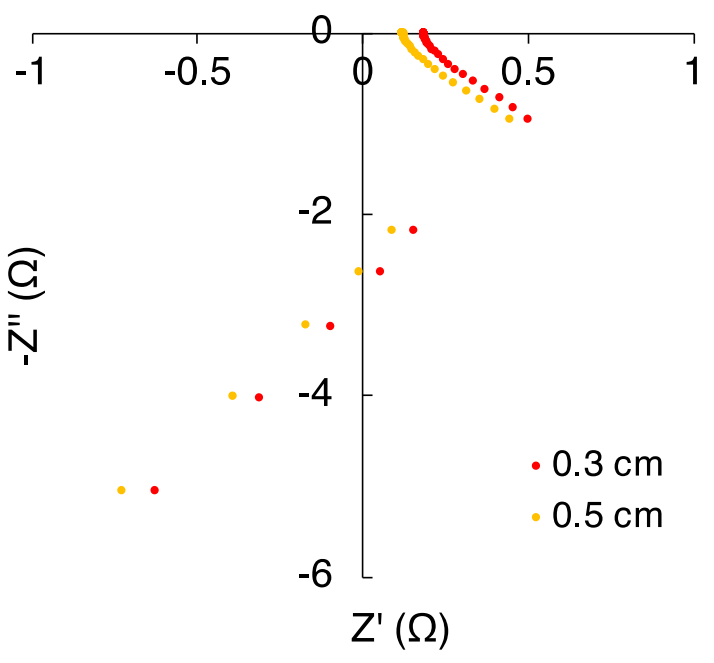

Figure 11 ACIS data for short circuit calibration measurement. 
$R=\rho \frac{l}{A}$

Here, $R$ is the electrical resistance of the electrode, $\rho$ is the specific resistivity, $l$ is the length, and $A$ is the cross-sectional area [20,46]. Therefore, the electrical resistance of the electrode is expected to be reduced as the cross-sectional area decreases, while the inductance effects maintain the same values because they are caused by the leads, and not by the cell specifications.

Regarding the final custom cell design as a result of this parametric study, it was decided to use threaded electrodes with $3 \mathrm{~mm}$ diameter and $7 \mathrm{~cm}$ length, of which $6 \mathrm{~cm}$ would be in contact with the cement paste and $1 \mathrm{~cm}$ would be outside the cell for connection of the WE and the RE.

The decision to use this electrode specification was made considering that the threaded texture did not have a significant effect on the effective surface area for the ACIS measurements but did significantly increase the electrode-sample contact to reduce the likelihood of debonding at that interface. The electrode length $(7 \mathrm{~cm})$ was selected to ensure a uniform current distribution, larger values of the EDLC, and effective surface area through the cement paste $[42,47,48]$. Finally, it was observed in Fig. $10 \mathrm{~b}$ that a decrease in the electrode diameter was able to reduce the parasitic effects, and it is expected that the lower total internal resistance of the cell would increase the fractional contribution of the cement bulk to the overall impedance measurements.

\section{Electrode material}

Figure 12 shows the influence of the electrode material on the measured ACIS spectra of $\mathrm{wPc}$ pastes. At early age, the ACIS measurements in the high frequency range and the inductance effects are not considerably affected by the choice of electrode materials among those tested here. However, at low frequencies it is possible to observe a difference in the part of the response that is attributed to diffusional processes, due to the variation in the electrode material having an impact on the reaction rates between the cement paste and the electrode $[45,49,50]$. At longer ages, there is a greater impact on the ACIS measurements due to the choice of electrode material.

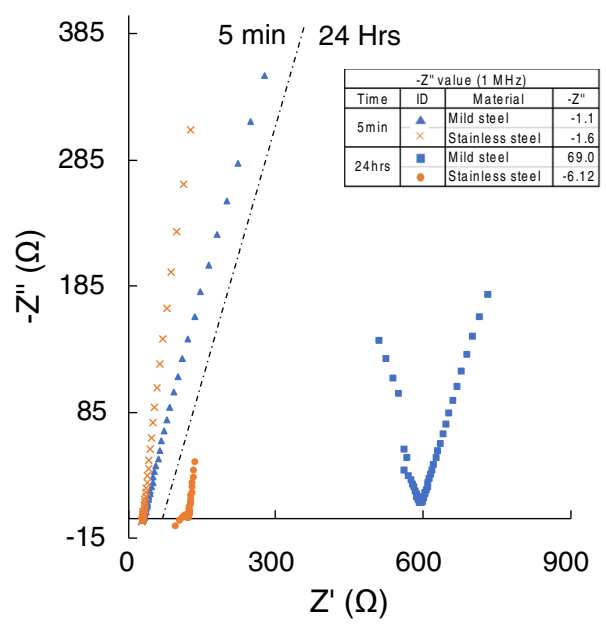

Figure 12 ACIS data for wPc pastes, for different electrode materials as noted.

The increase in resistance, the disappearance of the inductance effects, and the emergence of a high-frequency semicircular arc when using mild steel electrodes can all be related to the combination of the response of the cement microstructure development and the formation of a protective iron oxide film on the steel surface generated by the alkaline environment of the cement paste [51-53]. The electrode surface film has a strong influence on the ACIS measurements obtained using mild steel electrodes. Conversely, the ACIS measurements obtained with SS electrodes are determined mainly by the cement bulk and the electrode-cement interface $[49,52,54,55]$. This fact is attributed to the action exerted by the chromium-rich oxide film (passive film) on the SS electrode surface giving as a result a more stable electrode response. The reaction between the cement paste and the SS electrodes is slower than the reaction involving mild steel electrodes.

It is evident that the correct electrode material selection can enhance the ACIS measurements in terms of specific capacitance, diffusion rates, EDLC, accuracy, and performance [13, 55, 56]. Comparison of the ACIS results showed that SS electrodes are suitable in a highly alkaline environment, without affecting the impedance measurements and ensuring a stable electrode-cement interface and interaction, uniform current distribution, and better performance than mild steel electrodes.

Stainless steel and mild steel were considered suitable materials in this investigation. Other electrode materials, such as graphite or platinum, were 
not considered because of the single-use application and the higher cost.

\section{Electrode position}

Figure 13 shows the effects of electrode separation effects on the ACIS spectra of wPc pastes. Taking the electrode separation distance of the initial cell $(3 \mathrm{~cm})$ as a reference, the results at both ages show an increase in the impedance values of $Z^{\prime}$ axis (ohmic resistance) when the electrode separation is either increased or decreased. The low-frequency response, dominated by diffusional behaviour, appears significantly less sensitive to the electrode separation.

At $1.5 \mathrm{~cm}$ electrode separation, inductance increases slightly because of mutual inductance effects as the separation between the electrodes is insufficient, whereas at $6.0 \mathrm{~cm}$ electrode separation, inductance increases considerably as the mutual inductance decreases and the self-inductance of the leads increases.

Figure 14 shows the effects of the electrode positions on the impedance spectra of wPc pastes. The electrode positions studied were to have the electrodes located at the bottom (Fig. 1), top, and lateral faces of the polypropylene cell, without changing the distance between the SS electrodes.

At early age, the impedance measurements are not affected by the majority of the electrode positions. The only position which influences the impedance measurements is at the top of the cell, where the ohmic resistance and inductance effects increase. This tendency is probably due to cement bleeding and air

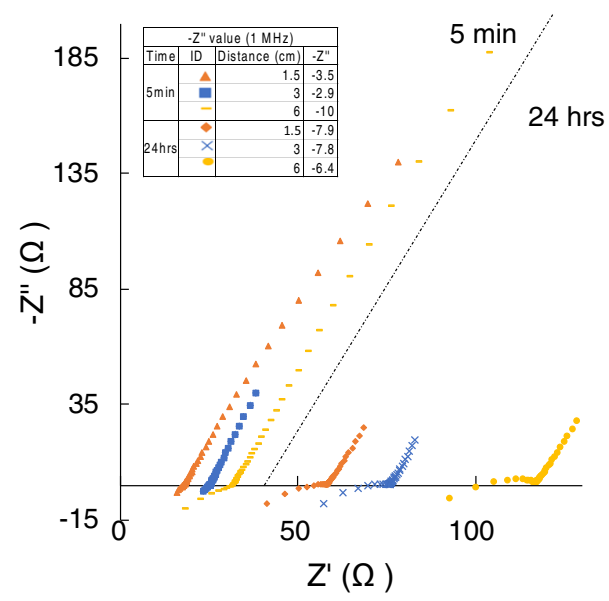

Figure 13 ACIS data for wPc pastes as a function of the separation between the electrodes.

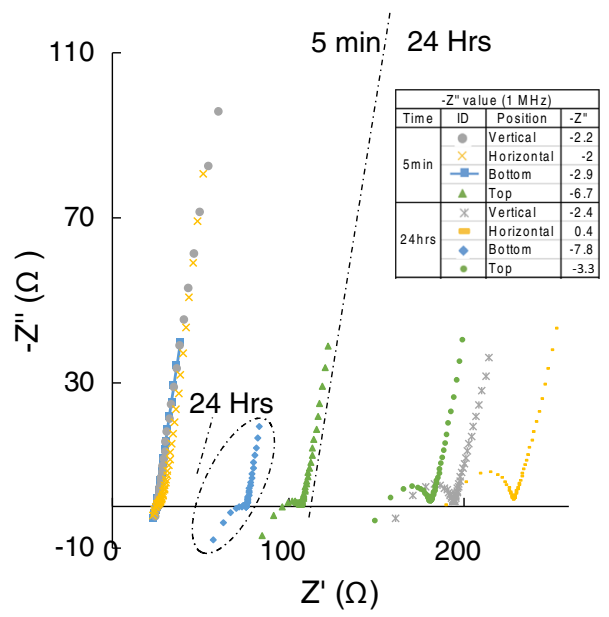

Figure 14 ACIS data for wPc pastes, as a function of the electrode position.

entrapment produced by electrode insertion from the top of the cell filled with cement paste.

At later age $(24 \mathrm{~h})$, the ACIS measurements and spectra are more notably affected by the electrode positions. The vertical, horizontal, and top electrode positions show an increase in the ohmic resistance values ( $Z^{\prime}$ axis) and the inductance effects at high frequencies are reduced, giving as a result the emergence of a semicircular arc. These ACIS measurements are the result of the combined response of the cement microstructural development and the ohmic resistance produced by the differential shrinkage and the potential cracking of cement generated by the thermal restrains and the stress/load of the electrodes position [14, 57].

The influence of the position of the electrodes in the ACIS measurements at later age is due to the sample geometry and the electrode direction changing the restraint of shrinkage of cement, leading to cracks that induce an increase in the ohmic resistance values [44, 58-62].

Based on these results and considering the practicalities of cell construction and loading, it was decided to position the electrodes at the bottom face of the custom cell since this location showed a better performance on the ACIS measurements, without cracks appearing in the hardened cement, and ensuring consistent measurement of the cement paste. 


\section{Calibration and measurement corrections}

Calibration experiments followed the same experimental procedure and the set-up used in the previous cell design test, as any change in the configuration affects the ACIS measurements and therefore the calibration values. The ACIS measurement corrections were carried out after verifying the reproducibility of the short-circuited custom cell design measurement, and considering the calibration measurements as an additive correction to the ACIS measurements [19-21, 63].

Figure 15 shows the impedance spectra before and after application of these corrections, for wPc at early age. After the correction, the impedance spectra show high-frequency data above the $Z^{\prime}$ axis, with a highfrequency semicircular arc, while the measurements at low frequencies do not change. For correct data interpretation, it is necessary to apply this correction to the raw ACIS measurements.

\section{Final cell design and ACIS data for white Portland cement hydration}

To select a cell design, the evaluation of ACIS measurements for different cell parameters was presented in the preceding sections. Figure 16 shows the custom cell design specification involved the use of threaded SS electrodes $(\phi 0.3 \times 7 \mathrm{~cm})$ and the cylindrical polypropylene container $(\phi 6 \times 11.2 \mathrm{~cm})$ used for the following experiments. The time between measurement acquisitions was every $5 \mathrm{~min}(0-24 \mathrm{~h})$,

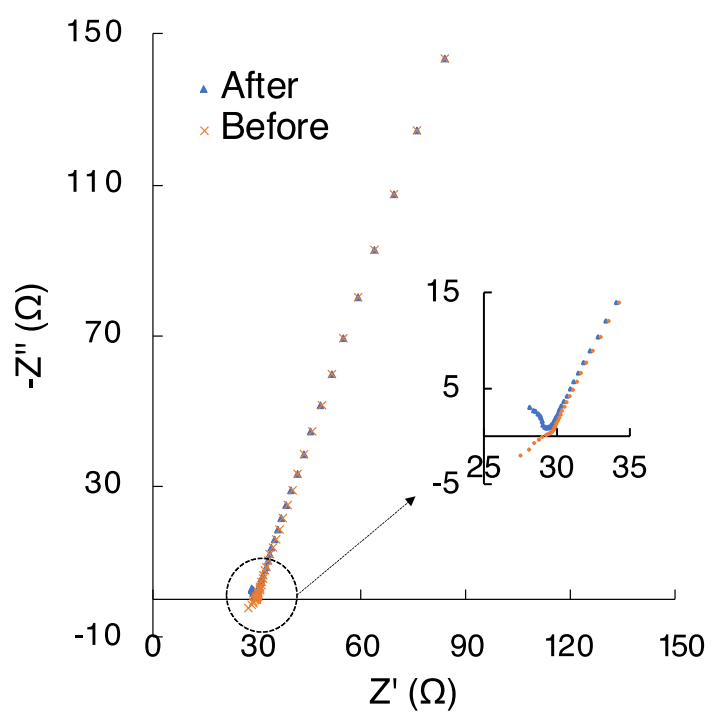

Figure 15 ACIS data for measurement correction of wPc system.

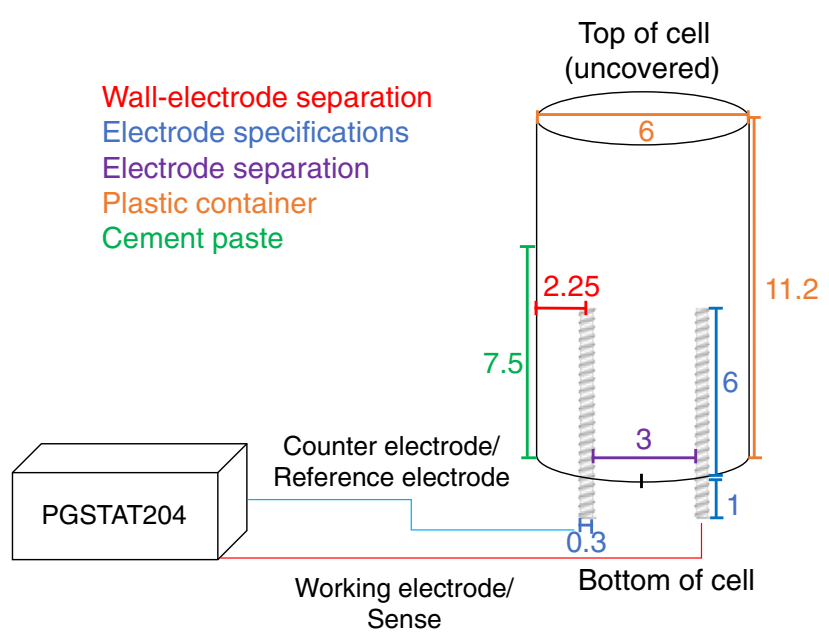

Figure 16 Final cell design diagram (scale in $\mathrm{cm}$ ).

$10 \mathrm{~min}(24-48 \mathrm{~h}), 15 \mathrm{~min}(48-72 \mathrm{~h})$, and $20 \mathrm{~min}$ (72-92 h). Subsequently, the impedance data were calibrated and corrected.

Figure 17a shows the ACIS spectra of wPc during the first $92 \mathrm{~h}$ after mixing. Before the first $3.5 \mathrm{~h}$, the inductance effects are removed from the ACIS spectra by application of the calibration and correction as described above. However, after $3.5 \mathrm{~h}$, inductance effects suddenly appear (followed by an increase in $\mathrm{Z}^{\prime}$ values), showing a decreasing trend which disappears after $30 \mathrm{~h}$. At longer ages and as the hydration proceeds, the emergence of semicircular arcs at high frequency is more developed, while the increase in $\mathrm{Z}^{\prime}$ axis values becomes slower as the thickness of the hydrated products increases and the hydration process slows [64-66].

The conductivity was obtained from the resistivity of the wPc paste by dividing the $Z^{\prime}$ axis intercept point of the impedance spectra into a cell constant. The cell constant was obtained by measuring the ACIS response of different concentrations of $\mathrm{NaOH}$ solutions of known conductivity [46, 67-70], using the cell shown in Fig. 16. Figure 17b shows the conductivity and resistivity as a function of time for wPc. On the first day of the hydration reaction, three perturbations are observed as the resistivity increases slightly and the conductivity drops quickly. At longer ages, the resistance increases rapidly, showing an increase in the amplitude and number of perturbations, while the conductivity decreases reaching a point where the changes in conductivity are minor.

Figure 17c shows a second perspective of the impedance spectra of $\mathrm{WPc}$, by plotting the real 

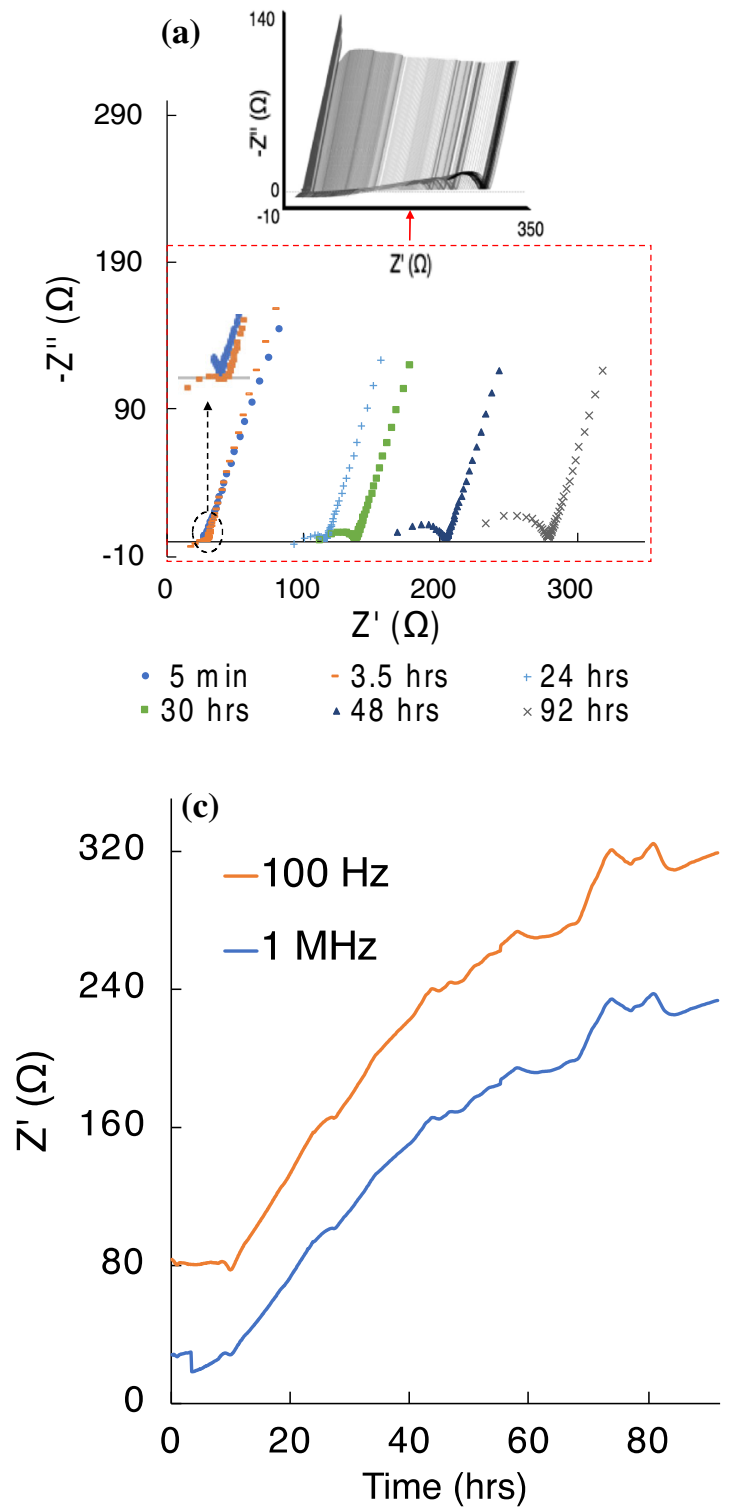

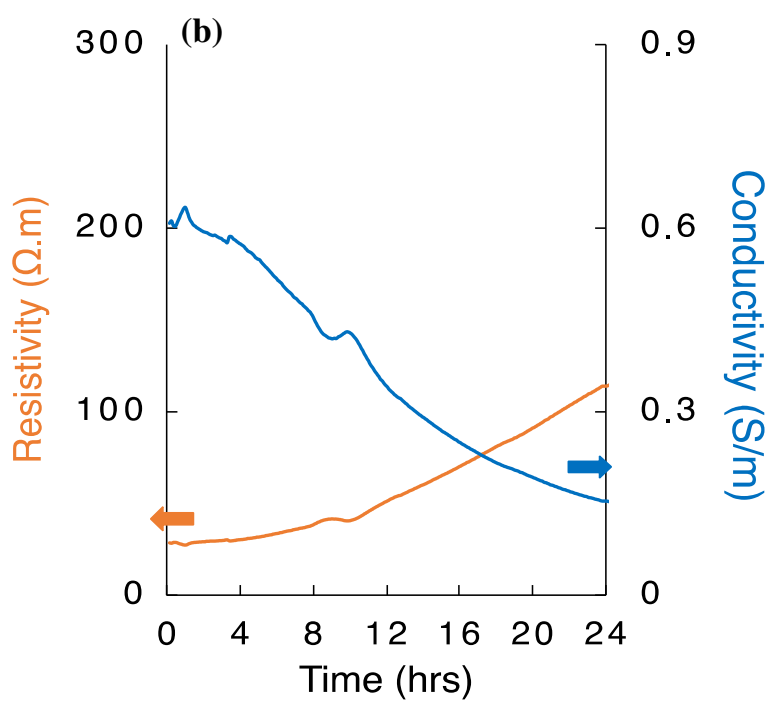

(d)

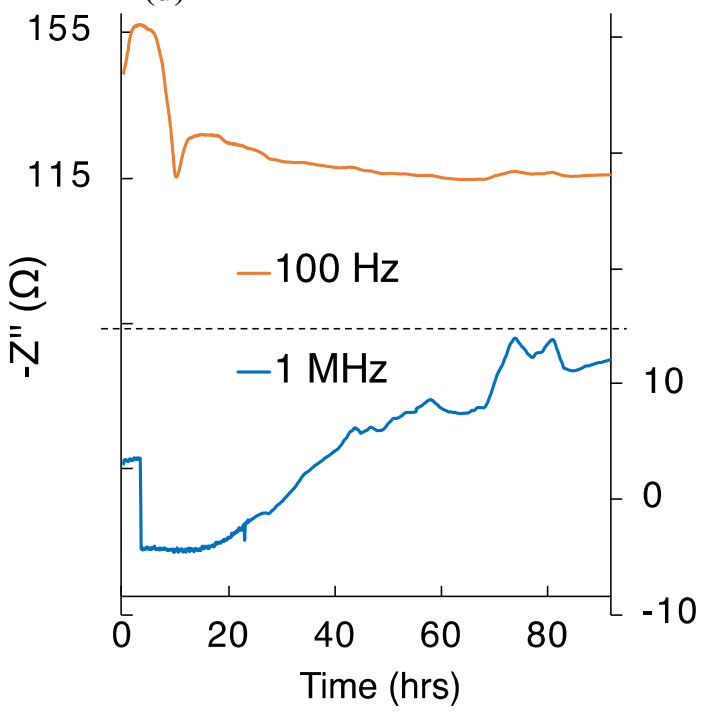

Figure 17 ACIS response of wPc paste as indicated in the legend: a Nyquist plots; $\mathbf{b}$ conductivity and resistivity; and for frequencies of at $100 \mathrm{~Hz}$ and $1 \mathrm{MHz}, \mathbf{c}$ the real component, and $\mathbf{d}$ the imaginary component.

component $\left(Z^{\prime}\right)$ against time for two different frequencies. At early ages, between 3.5 and $10 \mathrm{~h}$, the $\mathrm{Z}^{\prime}$ values at high frequencies decrease as inductance emerges (highlighted), while the $Z^{\prime}$ values at low frequencies change slightly. At longer ages, $Z^{\prime}$ values at both frequencies show an increasing resistance behaviour.

Figure $17 \mathrm{~d}$ shows a different perspective of the impedance spectra of $\mathrm{wPc}$ by plotting the imaginary component $\left(-Z^{\prime \prime}\right)$ against time. The results show small changes at high and low frequencies. To illustrate the inductance behaviour between 3.5 and $30 \mathrm{~h}$, - Z" values at $100 \mathrm{~Hz}$ and $1 \mathrm{MHz}$ are highlighted. At early ages, the $-Z^{\prime \prime}$ values at $1 \mathrm{MHz}$ rapidly decrease and become negative due to the emergence of inductance effects, while $-Z^{\prime \prime}$ values at $100 \mathrm{~Hz}$ decrease slowly, reaching a minimum value at $10 \mathrm{~h}$ and followed by a short increase period between 10 and $14 \mathrm{~h}$. At longer ages, an increasing tendency of $-Z^{\prime \prime}$ values is observed at $1 \mathrm{MHz}$, in which the - Z" values once more become positive at $30 \mathrm{~h}$ due to the disappearance of inductance effects. The $-Z^{\prime \prime}$ values at $100 \mathrm{~Hz}$ decrease until $50 \mathrm{~h}$, reaching a period with low activity.

Cement hydration is divided (usually on the basis of calorimetric results) into five stages: dissolution, 
induction/dormant, acceleration, deceleration/diffusion, and long-term reaction [1, 71, 72]. The chemical and microstructural processes taking place during these stages are also identifiable in the ACIS data. At early ages (dissolution and induction stages), the results show small impedance and resistivity values due to the high conductivity of the cement paste (with ions in the aqueous phase supplied by the rapid dissolution of soluble alkali and calcium sulphates), and limited solid phase microstructural development. At $3.5 \mathrm{~h}$ after mixing, the ACIS values at high frequencies are affected by the sudden emergence of inductance effects. Between the end of the induction period and the beginning of the acceleration period, the dissolution of $\mathrm{C}_{3} \mathrm{~S}$ and $\mathrm{C}_{2} \mathrm{~S}$ increases the ionic strength of the cement paste pore fluid, followed by the nucleation of $\mathrm{C}-\mathrm{S}-\mathrm{H}$ and initial crystallisation of $\mathrm{CH}$. At this point, the resistivity starts to decrease.

During the deceleration period, the heat flow and reaction rate of silicates decreases, and the microstructure is affected by water consumption, pore reduction, and space limitation. At this point, the results show increasing $Z^{\prime}$ values (Fig. 17c), and the inductance effects $\left(-Z^{\prime \prime}\right)$ remain unchanged. At approximately $10 \mathrm{~h}$, the low frequency values in Fig. $17 \mathrm{~b}$ decrease, while the $Z^{\prime}$ values in Fig. $17 \mathrm{c}$ show a perturbation at both high and low frequencies.

At the end of the deceleration period and during the long-term reaction period $(\sim 15 \mathrm{~h})$, the inductance effects $\left(-Z^{\prime \prime}\right)$ start to decrease, until they disappear at $30 \mathrm{~h}$. The $Z^{\prime}$ values keep increasing at both frequencies, probably because of the microstructural development, reduced water content, and the partial closure and eventual depercolation of the pore structure.

At longer ages ( $>30 \mathrm{~h}$ ), a high-frequency arc starts to emerge, and while the microstructure continues developing slowly, the diameter of the high-frequency arc increases, as can be observed in Fig. 17a. The conductivity decreases to reach a certain point where no further significant changes can be appreciated, while the resistivity keeps increasing due to the slow microstructural development $[8,71,73]$.

\section{Conclusions}

This study has assessed the electrochemical cell design and ACIS measurements during cement hydration in the early stages of hydration, in both the fresh (fluid) and hardened states. The results demonstrate the importance of the correct assessment of the parameters (e.g. electrode, lead and parasitic effects, and procedure) in the cell design to reduce the parasitic effects that appear in ACIS data. A good correlation between the ACIS measurements and the cement hydration stages was obtained. However, due to the limited solid phase microstructural development and the highly conductive condition of cement at early hydration periods, the parasitic effects could not be fully corrected until the cement had hydrated sufficiently to yield a microstructure that was able to raise the resistivity of the paste.

It is therefore possible to highlight the following conclusions:

1. ACIS response and parasitic effects are directly affected by electrode effects and cell design.

2. Cement conductivity and resistivity behaviour, and their variation as a function of time during hydration, correlate with existing conceptual models developed from calorimetric and other data.

3. ACIS has been shown to be a sensitive and versatile technique for assessing the different stages of cement hydration, from the fresh to the hardened state, which is very difficult to probe truly continuously by any other single technique in a time-resolved manner. However, in order to fully understand this process and its microstructural development, the behaviour and interpretation of ACIS measurements and the parasitic effects that complicate the data processing and analysis need further investigation, supported by other characterisation techniques.

\section{Acknowledgements}

This study was funded by the Science and Technology Council of Mexico (Consejo Nacional de Ciencia y Tecnología, CONACYT), and the European Union through the 7th Framework Programme (European Research Council Starting Grant \#335928). 


\section{Author contributions}

ASG and JP contributed to methodology, experimental plan, interpretation of data, and draft preparation; ASG contributed to experimental work and data analysis; JP contributed to funding acquisition, supervision, resources, and review \& editing.

\section{Compliance with ethical standards}

Conflict of interest The authors do not hold any conflict of interest related to the work described in this article.

Open Access This article is licensed under a Creative Commons Attribution 4.0 International License, which permits use, sharing, adaptation, distribution and reproduction in any medium or format, as long as you give appropriate credit to the original author(s) and the source, provide a link to the Creative Commons licence, and indicate if changes were made. The images or other third party material in this article are included in the article's Creative Commons licence, unless indicated otherwise in a credit line to the material. If material is not included in the article's Creative Commons licence and your intended use is not permitted by statutory regulation or exceeds the permitted use, you will need to obtain permission directly from the copyright holder. To view a copy of this licence, visit http://creativecommons.org/licen ses/by/4.0/.

\section{References}

[1] Mehta PK, Monteiro PJM (2006) Concrete: microstructure, properties, and materials, 3rd edn. McGraw-Hill, California

[2] Hewlett PC, Liska M (2019) Lea's chemistry of cement and concrete, 5th edn. Elsevier, United Kingdom

[3] Kohlhaas B (1983) Cement engineers' handbook, 4th edn. Bauverlag, Wiesbaden; Berlin

[4] Taylor HFW (1997) Cement chemistry, 2nd edn. Thomas Telford, London

[5] Mason TO, Ford SJ, Shane JD, Hwang J-H, Edwards DD (1998) Experimental limitations in impedance spectroscopy of materials systems. Adv Cem Res 10:143-150

[6] Hsieh G, Mason TO, Pederson LR (1996) Experimental limitations in impedance spectroscopy: part II-electrode artifacts three-point measurements on Pt/YSZ. Solid State Ionics 91:203-212
[7] Hwang JH, Kirkpatrick KS, Mason TO, Garboczi EJ (1997) Experimental limitations in impedance spectroscopy: part IV. Electrode contact effects. Solid State Ionics 98:93-104

[8] Spragg R, Villani C, Snyder K, Bentz D, Bullard J, Weiss J (2013) Factors that influence electrical resistivity measurements in cementitious systems. Transp Res Rec 2342:1-12

[9] Hu X, Shi C, Liu X, Zhang J, de Schutter G (2019) A review on microstructural characterization of cement-based materials by AC impedance spectroscopy. Cem Concr Compos 100:1-14

[10] Christensen BJ et al (1994) Impedance spectroscopy of hydrating cement-based materials: measurement, interpretation, and application. J Am Ceram Soc 77(11):2789-2804

[11] Yuan X-Z, Song C, Wang H, Zhang J (2010) Electrochemical impedance spectroscopy in PEM fuel cells. Springer, London

[12] Orazem ME, Tribollet B (2008) Electrochemical impedance spectroscopy. Wiley, Hoboken

[13] Barsoukov E, Macdonald JR (2005) Impedance spectroscopy theory, experiment, and applications, 2nd edn. Wiley-Interscience, Hoboken

[14] Cormack SL, Macphee DE, Sinclair DC (1998) An AC impedance spectroscopy study of hydrated cement pastes. Adv Cem Res 10(4):151-159

[15] Gamry Instruments (2010) Verification of low impedance: EIS using a $1 \mathrm{~m} \Omega$ resistor, pp 1-6

[16] Macphee DE, Sinclair DC, Stubbs SL (1996) Electrical characterization of pore reduced cement by impedance spectroscopy. J Mater Sci Lett 15:1566-1568

[17] Lai W (2007) Impedance spectroscopy as a tool for the electrochemical study of mixed conducting ceria. Ph.D. thesis, California Institute of Technology

[18] Metrohm Autolab BV (2011) Electrochemical cell setup, Autolab application note EC08, pp 1-3

[19] Prabhakaran S, Sullivan CR (2002) Impedance-analyzer measurements of high-frequency power passives: techniques for high power and low impedance. In: 2002 IEEE industry applications conference. 37th IAS Annual Meeting, pp 1360-1367

[20] Raikova G, Carpanese P, Stoynov Z, Vladikova D, Viviani M, Barbucei A (2009) Inductance correction in impedance studies of solid oxide fuel cells. Bulg Chem Commun 41(2):199-206

[21] Soboleva T, Xie Z, Shi Z, Tsang E, Navessin T, Holdcroft S (2008) Investigation of the through-plane impedance technique for evaluation of anisotropy of proton conducting polymer membranes. J Electroanal Chem 622(2):145-152

[22] Sosa Gallardo AF (2016) The study of cement hydration by alternating current impedance spectroscopy and isothermal calorimetry, MSc thesis, University of Sheffield 
[23] Pang X, Bentz DP, Meyer C, Funkhouser GP, Darbe R (2013) A comparison study of Portland cement hydration kinetics as measured by chemical shrinkage and isothermal calorimetry. Cem Concr Compos 39:23-32

[24] Lin F, Meyer C (2009) Hydration kinetics modeling of Portland cement considering the effects of curing temperature and applied pressure. Cem Concr Res 39(4):255-265

[25] Metrohm Autolab BV (n.d.) Raw data from FRA measurements, Technical note 15, pp 1-15

[26] Metrohm Autolab BV (2011) Electrochemical impedance spectroscopy (EIS), Part 6-measuring raw signals in EIS, pp 1-3

[27] Zia AI, Mukhopadhyay SC (2016) Impedance spectroscopy and experimental setup. In: Electrochemical sensing: carcinogens in beverages. Springer International, pp 21-67

[28] Hirschorn B, Tribollet B, Orazem ME (2008) On selection of the perturbation amplitude required to avoid nonlinear effects in impedance measurements. Isr J Chem 48:133-142

[29] Yerokhin A, Parfenov EV, Liang CJ, Mukaeva VR, Matthews A (2013) System linearity quantification for in-situ impedance spectroscopy of plasma electrolytic oxidation. Electrochem Commun 27:137-140

[30] Giner-Sanz JJ, Ortega EM, Pérez-Herranz V (2017) Harmonic analysis based method for perturbation amplitude optimization for EIS measurements. J Electrochem Soc 164(13):H918-H924

[31] Lasia A (2014) Electrochemical impedance spectroscopy and its applications. Springer, New York

[32] Paul CR (2010) Partial inductance. IEEE EMC Soc Newslett 226:34-42

[33] Shah SJ (2001) Field wiring and noise considerations for analog signals, Natl Instrum Corp, pp 1-22

[34] Reid O, Saleh FS, Easton EB (2013) Determining electrochemically active surface area in PEM fuel cell electrodes with electrochemical impedance spectroscopy and its application to catalyst durability. Electrochim Acta 114:278-284

[35] Breit G (1922) High-frequency resistance of inductance coils. Sci Papers Natl Bur Standards 17(4):569-587

[36] Coffin JG (1906) The influence of frequency upon the selfinductance of coils. Proc Am Acad Arts Sci 41(34):275-296

[37] BioLogic Science Instruments (2010) Application note \#5: precautions for good impedance measurements, pp 1-5

[38] Chomerics (n.d.) EMI shielding theory \& gasket design guide. In: EMI shielding engineering handbook, pp 191-220

[39] Bünzli C, Kaiser H, Novák P (2015) Important aspects for reliable electrochemical impedance spectroscopy measurements of Li-ion battery electrodes. J Electrochem Soc 162(1):A218-A222

[40] Hsieh G, Mason TO, Garboczi EJ, Pederson LR (1997) Experimental limitations in impedance spectroscopy: Part
III. Effect of reference electrode geometry/position. Solid State Ionics 96(3-4):153-172

[41] Grubb JA, Limaye HS, Kakade AM (2007) Testing pH of concrete. Concr Int 29(4):78-83

[42] Jiang X, Nešić S, Huet F (2009) The effect of electrode size on electrochemical noise measurements and the role of chloride on localized $\mathrm{CO}_{2}$ corrosion of mild steel. In: Corrosion 2009, NACE International, \#NACE-09575

[43] Ogihara N, Itou Y, Sasaki T, Takeuchi Y (2015) Impedance spectroscopy characterization of porous electrodes under different electrode thickness using a symmetric cell for highperformance lithium-ion batteries. J Phys Chem C 119:4612-4619

[44] Zhou H, Tilton RD, White LR (2006) The role of electrode impedance and electrode geometry in the design of microelectrode systems. J Colloid Interface Sci 297(2):819-831

[45] Mohtashami S (2011) Electrochemical properties of flexible electrodes for implanted neuromuscular excitation applications. MASc Thesis, McMaster University

[46] National Institute of Standards and Technology (2004) Primary standards and standard reference materials for electrolytic conductivity, pp 1-31

[47] Wu Z, Li L, Yan JM, Zhang XB (2017) Materials design and system construction for conventional and new-concept supercapacitors. Adv Sci 4:1-48

[48] Suda Y, Mizutani A, Harigai T, Takikawa H, Ue H, Umeda Y (2016) Influences of internal resistance and specific surface area of electrode materials on characteristics of electric double layer capacitors. Am Inst Phys Conf Proc 1807(020022):1-12

[49] Li B, Huan Y, Zhang W (2017) Passivation and corrosion behavior of P355 carbon steel in simulated concrete pore solution at $\mathrm{pH} 12.5$ to 14 . Int $\mathrm{J}$ Electrochem Sci 12:10402-10420

[50] Lee SH, Jung JH, Chae YM, Suh JKF, Kang JY (2010) Fabrication and characterization of implantable and flexible nerve cuff electrodes with $\mathrm{Pt}$, Ir and IrO films deposited by RF sputtering. J Micromech Microeng 20(3):035015

[51] Nürnberger U (1996) Stainless steel in concrete-state of the art report. Maney, London

[52] Nishikata A, Ichihara Y, Tsuru T (1995) An application of electrochemical impedance spectroscopy to atmospheric corrosion study. Corros Sci 37(6):897-911

[53] Hamdy AS, El-Shenaw E, El-Bitar T (2006) Electrochemical impedance spectroscopy study of the corrosion behavior of some niobium bearing stainless steels in $3.5 \% \mathrm{NaCl}$. Int $\mathrm{J}$ Electrochem Sci 1(4):171-180

[54] Alves VA, Brett CMA (2001) Characterisation of passive films formed on mild steels in bicarbonate solution by EIS. Electrochim Acta 47(13-14):2081-2091 
[55] Hu J, Koleva DA, De Wit JHW, Petrov P, Van Breugel K (2010) Corrosion performance of carbon steel in micellecontaining cement extract. ECS Trans 28(24):113-121

[56] Arminox (1999) Corrosion aspects of galvanic coupling between carbon steel and stainless steel reinforcement in concrete. Brondby

[57] Ford SJ, Mason TO, Christensen BJ, Coverdale RT, Jennings HM, Garboczi EJ (1995) Electrode configurations and impedance spectra of cement pastes. J Mater Sci 30(5):1217-1224 https://doi.org/10.1007/BF00356122

[58] Cesiulis H, Tsyntsaru N, Ramanavicius A, Ragoisha G (2016) The study of thin films by electrochemical impedance spectroscopy. In: Nanostructures and thin films for multifunctional applications. Springer International, Moldova, pp 3-43

[59] Ahmed R, Reifsnider K (2011) Study of influence of electrode geometry on impedance spectroscopy. Int J Electrochem Sci 6:1159-1174

[60] Zhang F et al (2014) Reference and counter electrode positions affect electrochemical characterization of bioanodes in different bioelectrochemical systems. Biotechnol Bioeng 111:1931-1939

[61] Yan W, Hong S, Chaoshi R (2006) Optimum design of electrode structure and parameters in electrical impedance tomography. Physiol Meas 27(3):291-306

[62] Corporate Circular: BTD2007/11 Horizontal reinforcement for crack control in walls and wall type piers, Bridge technical direction

[63] Sosa Gallardo AF, Provis JL (2020) Early-age characterisation of Portland cement by impedance spectroscopy. Adv Cem Res, manuscript under review

[64] Navi P, Pignat C (1996) Simulation of cement hydration and the connectivity of the capillary pore space. Adv Cem Based Mater 4(2):58-67
[65] Gu P, Xie P, Beaudoin JJ, Brousseau R (1993) A.C. impedance spectroscopy (II): microstructural characterization of hydrating cement-silica fume systems. Cem Concr Res 23(1):157-168

[66] Cruz JM, Fita IC, Soriano L, Payá J, Borrachero MV (2013) The use of electrical impedance spectroscopy for monitoring the hydration products of Portland cement mortars with high percentage of pozzolans. Cem Concr Res 50:51-61

[67] Heath JP, Harding JH, Sinclair DC, Dean JS (2019) The analysis of impedance spectra for core-shell microstructures: why a multiformalism approach is essential. Adv Funct Mater 29(38):1-10

[68] Provis JL, Walls PA, van Deventer JSJ (2008) Geopolymerisation kinetics. 3. Effects of $\mathrm{Cs}$ and $\mathrm{Sr}$ salts. Chem Eng Sci 63:4480-4489

[69] LGC Limited (2003) Preparation of calibration curves: a guide to best practice. LGC/VAM/2003/032, pp 1-27

[70] Rosemount Analytical (2010) Conductance data for commonly used chemicals, 44-6039/rev.B. Emerson Process Management, Irvine

[71] Bullard JW et al (2011) Mechanisms of cement hydration. Cem Concr Res 41(12):1208-1223

[72] Ramachandran VS (1995) Concrete admixtures handbook. Properties, science, and technology, 2nd ed. Noyes Publications, Ottawa

[73] Thomas JJ et al (2011) Modeling and simulation of cement hydration kinetics and microstructure development. Cem Concr Res 41(12):1257-1278

Publisher's Note Springer Nature remains neutral with regard to jurisdictional claims in published maps and institutional affiliations. 